\title{
Egypt's Capital Market Firm-Specific Fundamentals Pre-financial crisis
}

\section{Ahmed Mohamed Moataz Abd El Salam}

يقوم الباحث في هذه الدراسة بتطبيق نموذج الأربعة عوامل Fama and) من اجل تحديد سمات السوق المصري. تتمثل البيانات في جميع الثركات المتداولة في البورصة المصرية باستثناء المؤسسات المالية و الشركات ذات ذات

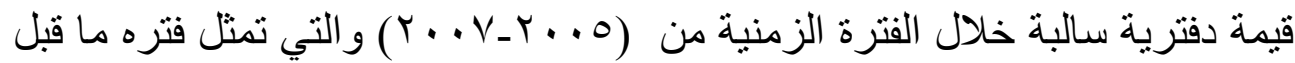

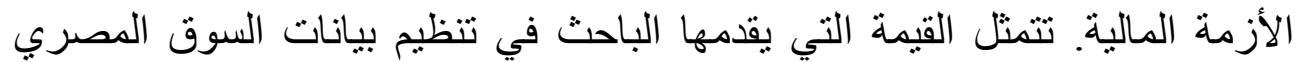

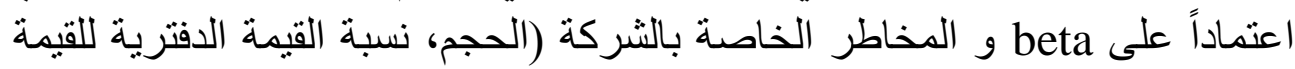

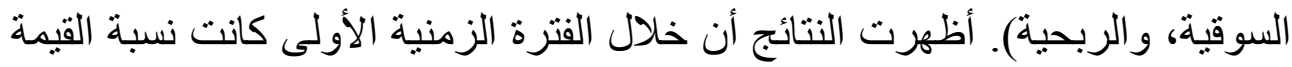

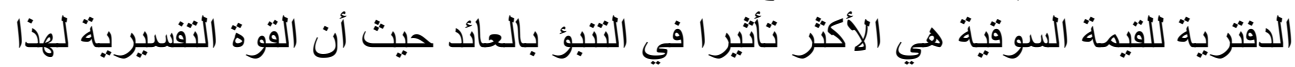
المتغير بلغت 0 \. • \% من العائد.

\section{Abstract:}

This study documents four factor sensititivities of excess returns in Egypt during the economic period from (2005-2007) which represent Pre-financial crisis economic environment. This study is placed within deductive research paradigm that evaluates the extent to which idiosyncratic risk factors organize market facts during (2005 -2007)that signifying the economic environment pre-financial crisis based on beta and firm-specific fundamentals, namely, size, value, and accounting earnings. 


\section{Introduction:}

In this study, a proxy specifications of (Fama and French, 2014) four-factor model is estimated in order to produce stylized facts of the Egyptian market. The data set is the panel of all publicly traded firms, excluding financial and negative book value of equity firms.

The capital asset pricing model aggregates all risk into only one risk factor which is the market risk because it assumes that all other risks can be removed through diversification. However, in reality there are many sources of risk that are not washed out through diversification, that investors should consider in determining risk-return relationship which is explained by Fama and French 2014.

The contribution to the extant literature is two-fold: [1] organizing Egyptian market data based on beta and firm-specific fundamentals, namely, size, value, and accounting earnings. The study organizes Egyptian capital market facts based on four factors: market beta, size, value, and accounting earnings. In particular, documenting a factor loading for accounting earnings within an empirical asset pricing model defines a major contribution for this study. Unlike those pertaining to the first three factors, empirical documents of the accounting earnings factor loading are rather, if any, scant.

The researcher stresses the style pioneered by Fama and French in terms of taking finance research away from pure hypothesis testing and learning directly from data. This is done in this study by spelling out empirical regularities of the Egyptian 
market using a proxy specification of Fama and French fourfactor model.

\section{Literature review:}

An individual asset total risk consists of two main components [1] systematic risk, [2] unsystematic risk. The former risk measures the asset covariance with the market, while the later risk measures security-specific characteristics that are separate from the economy, that is:

$$
\text { Total risk }=\text { systematic } \text { risk }+ \text { unsystematic risk }
$$

Capital asset pricing model (CAPM) suggests that the market risk (systematic risk) is the only priced risk factor and that the firm specific risk can be washed off via diversification. The capital asset pricing model aggregates all risk into only one risk factor which is the market risk because it assumes that all other risks (unsystematic risk) can be removed through diversification. However, in reality there are many sources of risk that are not washed out through diversification, that investors should consider in determining risk-return relationship.

Various theories suggest that idiosyncratic risk/volatility can be priced in asset returns because investors do not fully diversify their portfolios. That is CAPM suggests that idiosyncratic risk can be washed out (perfectly diversified away) as investors hold a proportion of a well diversified market portfolio. However, in reality this is not always the case as suggested by Levy (1978) and Merton (1987) theories which also 
state that under diversification investors demand a return compensation for bearing idiosyncratic risk.

Ross (1976) formulated the arbitrage pricing theory (APT) that combines multiple factors rather than a single factor in predicting stock returns. It suggested that the relationship between portfolio returns and asset returns is determined through a combination of various independent macro-economic factors. For example, If we assume that investors are broadly diversified, but the economy may still have many other sources of risks such as shifts in stock index levels, interest rates, inflation, changes in GNP or other broad macro-economic factors that are difficult to be washed out through diversification. Therefore investors shouldn't care solely about the market portfolio, but also they should care about such other sources of risk.

Chen (1983) compared the arbitrage pricing theory with the capital asset pricing model and found that the APT could explain a statistically significant portion of the CAPM residual variance, but the CAPM could not explain the APT residuals. This is strong evidence that the APT is a more reasonable model for explaining the cross-sectional variance in asset returns.

Many studies examined the impact of the APT on explaining asset returns. Factors that were examined most are size, book-to-market equity, earnings, and variance of asset returns. Fama and French $(1992,1993,1995)$ focused on only two risk factors which are company size and book-to-market equity and they found an evidence on their ability to explain asset returns better that the market risk alone. 
Hamao (1988) investigated the performance of APT for securities traded on Japanese equity market. He examined six macroeconomic factors including industrial production, inflation, investor confidence, interest rate, foreign exchange, and oil prices. The results show that, firstly, the expected inflation plays an important role in explaining Japanese stock returns, while the changes in industrial production have a weak role in explaining stock returns. In addition, the changes in oil prices and foreign exchange are not priced in the stock market. And finally they found that the market beta does not provide better explanation than other macroeconomic state variables.

Antoniou et al. (1998) examined the role of APT in explaining future returns of securities traded in the London stock exchange. They analyzed two samples and found that the unexpected inflation, the money supply, and excess returns on market portfolio helps in predicting future securities returns as they provided the same prices of risk in the two samples

Generally, most studies about APT shows that three to five factors are sufficient to explain the observed returns, adding more factors does not improve the result substantially. That is the APT model is more general. Many factors (not just the market portfolio) may explain asset returns. For each factor the appropriate measure of risk is the sensitivity of asset returns to changes in the factor. For normally distributed returns the sensitivity is corresponding to the beta (or systematic risk) of the CAPM. (Copeland et al, 2005).

The explanatory power of beta came into question in the late 1970s as a growing number of empirical studies suggests the .

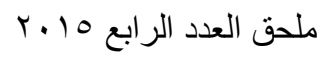


existence of additional factors which are relevant for asset pricing and beta, among these variables are size (measured by market capitalization of firm's common stock), ratio of book to market equity (the accounting value of firm equity divided by its market capitalization), and earning yield (the firm reported accounting net profit divided by price per share(earning/price)).

Ball (1978) suggests that the E/P ratio is a proxy for all unnamed factors in expected returns (i.e. the E/P explain the portion of security returns that not explained by Beta). He found that $\mathrm{E} / \mathrm{P}$ increases (prices are lower relative to earnings) with increase in risks and expected returns whatever the unnamed sources of risk. Thus, if the CAPM is an incomplete specification of priced risk, it is reasonable to expect that E/P might explain the portion of expected return that is compensation for risk variables omitted from the tests. Ball's proxy argument for E/P might also apply to size (ME), leverage, and book-to-market equity. All these variables can be regarded as different ways to scale stock prices, to extract the information in prices about risk and expected returns.

Dividend yield, the ratio of cash dividend to price, has also been shown to have cross-sectional return predictability. Litzenberger and Ramas wamy (1979) show a significant positive but non-linear relationship between dividend yield and return of common stocks for the 1936-1977 period (the evidence consistent with the Tax-Clientele CAPM ).He also indicate that whether the effect of dividend yields on common stock returns can be attributed to taxes or is due to some omitted variable (s) still remains an open question. 
On the other hand, Daniel and Titman (1997) is concerned with book to market and size loadings, they test whether the high return of high book to market and small size stock are attributed to their factor loadings or not. They are concerned with factors that are directly associated with size and book-to-market and with premiums associated with these factors. They found that there is no separate risk factor associated with high or law bookto-market firms and also there is no return premium associated with any of Fama \& French three factors.

Both Banz (1981) and Reinganum (1981) tested the relationship between firm size and expected stock returns in NYSE and AMEX. The results of both confirmed that stocks of small firms results in higher returns which means that whether the market is inefficient or that the CAPM is miss specified or both.

Basu (1983) argued that size ratio effect is a proxy for P/E effect. He examined the effect of earnings' yield and firm size on U.S. common stock returns and found that the earnings/price ratio has a significant effect on stock returns in tests that also include size and market $\beta$. That is firms with high $\mathrm{E} / \mathrm{P}$ earn higher returns even when controlling for firm size (i.e. after the effect of size, as measured by the market value of common stock, was randomized across the high and low E/P groups). He also found that the effect of firm size disappeared after controlling for differences in risk and $\mathrm{E} / \mathrm{P}$ ratios which indicates that, in contradiction with Reinganum (1981), the E/P is not a proxy for size effect. He also suggested that both $\mathrm{E} / \mathrm{P}$ ratios effect and size effect do not have a direct effect on expected stock reteturns and _.

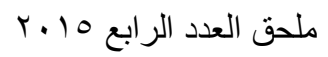


that they are just proxies for other fundamental determinants of expected returns for common stocks.

Chan et.al (1991) confirm the existence of a "size effect" in Japan during the period 1971 to 1988; he finds that after controlling for market risk and other fundamental variables small firms tend to earn higher returns than large firms. However, the statistical significance of the size variable is highly dependent on the model and time period specified so in some cases it is not significant.

The cross sectional behavior of common stocks returns in united states and different equity markets around the world have been studied by Hawawini and Keim (2000) they finds that CAPM is not sufficiently explain differences in common stock returns in those markets and both firm size and book to market value have a significant effect on returns on those markets. However those variables' return premiums are not correlated across different markets. As the results indicates that in all countries except Korea, the size premium is positive and varies across markets, it's most significant in Australia (5.73\%) and Mexico ( $4.16 \%)$ and is least significant in Canada (0.44\%) and united kingdom $(0.40 \%)$.

Fama and French (1992) were the first to combine size and book-to-market equity to capture the cross-sectional variation in average stock returns associated with market $\beta$, size, leverage, book-to-market equity, and earnings-price ratios. They estimate return using this equation $\mathrm{Ri}=\alpha+\mathrm{a} 1 \beta \mathrm{i}+\Sigma$ aj cij + ei and found that beta has a limited explanatory power, whether it was used alone or in combination with other variables; Also size, E/P.

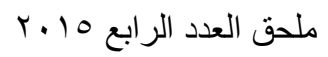


leverage, and book-to-market equity were found to have an explanatory power when used alone. While, in combinations, they found that size and book to market equity washed out the roles of both leverage and E/P. that is size and $\mathrm{B} / \mathrm{M}$ equity play the major role in explaining the variations in risk-return relationships associated with size, E/P, B/M equity, and leverage for stocks traded in NYSE, Amex, and NASDAQ during the period from 1963 to 1990.

In addition, they found that size and market beta is not correlated that is each one independently contributes to explain expected returns. So, they suggested that size and book to market equity are two additional risk factors that should be added to the market beta in order to better predict future returns.

Fama and French (1993) started from the point that the value and size variables are omitted risk factors that should be considered in explaining future returns as suggested by Fama and French (1992).

They proposed a three-factor model in which the expected return in excess of the risk-free rate $[E(R m)-R f]$ is explained by three major risk factors; [1] $(\mathrm{RM}-\mathrm{RF})$, the excess return on abroad market portfolio. [2]SMB the difference between the return on a portfolio of small stocks and the return on a portfolio of large stocks (SMB, small minus big).[3] HML the difference between the return on a portfolio of high book- to- 
market stocks and the return on a portfolio of low book-tomarket stocks (HML, high minus low). This is expressed by:

$\mathrm{Ri}-\mathrm{Rf}=\alpha \mathrm{i}+$ bi $(\mathrm{Rm}-\mathrm{Rf})+\mathrm{Si} \mathrm{SMB}+\mathrm{hi} \mathrm{HML}+\varepsilon \mathrm{i}$

Where $\mathrm{Ri}$ - Rf is excess return, $\mathrm{E}(\mathrm{Rm}-\mathrm{Rf}), \mathrm{E}(\mathrm{SMB})$, and $\mathrm{E}(\mathrm{HML})$ are expected premiums, and the factor sensitivities or loadings bi, $\mathrm{Si}$, hi are the slopes in the time-series regression.

This equation states that if CAPM is true, then the risk premiums associated with the size effect (SMB) and the value effect (HML) should be zero. This is not appeared in the empirical results. It also states that if three factor model covers all sources of risks, $\alpha \mathrm{i}$ ("alpha") will on average equal zero.

By applying the three factor model Fama and French (1993) found that size and book-to-market combined to the market factor explains most of the variations in stocks return because the intercepts from three factor regressions are close to zero. That is the proposed three factors seem to do a good job explaining the cross-section of average stock returns.

Even though Fama and French (1993) proposed model receive much empirical confirmation, it was criticized mainly for its lack of economic foundation (i.e. it is empirically inspired and lacks strong theoretical foundations). That is Size and BE/ME remain an arbitrary indicator variables that is for unexplained economic reasons are related to risk factors in returns ( Gaunt 2004; Chan et.al 1991; Danial et. al 2001).

and French (1995) tried to enhance the empirical findings of Fama and French $(1992,1993)$ by establishing a theoretical 
foundation that could economically explain such findings. They addressed the question of what is the underlying economic state variables that produce variation in earnings and returns related to size and $\mathrm{BE} / \mathrm{ME}$ or are returns and earnings common factors are the same factors (i.e. is the behavior of stock prices, in relation to size and book-to-market-equity, is consistent with the behavior of earnings).

The empirical results shows that firms with low BE/ME (a high stock price relative to book value) have high average returns on capital (growth stocks) and also firms with low BE/ME (a high stock price relative to book value) have high earnings on book equity this is typical of well performing firms. This finding is consistent with Penman (1991) who finds that the high ROE for high $\mathrm{P} / \mathrm{B}$ portfolios are high in subsequent years and the low ROE for low P/B portfolios are low in subsequent years. They also found that Size is also related to profitability. Controlling for $\mathrm{BE} / \mathrm{ME}$, small stocks tend to have lower earnings on book equity than do big stocks. However, they can't find clear cut evidence that the book-to-market factor in earnings drives the book-tomarket factor in returns. They suppose that this negative result is caused by noise in the measures of shocks to expected earnings.

Many studies tested the ability of Fama \& French three factor model in explaining stock returns and found that the model has a strong ability in predicting future average stock returns over an extended period. Such as $\mathrm{Ou} \mathrm{Hu}$ (2007), Simpson and Ramchander (2008), Simalai (2009), and Nguyen et al., (2009) The role that profitability plays in expecting stock returns was

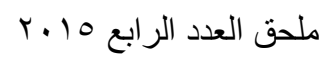


examined by Jegadeesh and Titman (1993), they found that stocks that have high past profitability result in higher returns than stocks with low past profitability in the first three to twelve month holding periods, however, they found that in the following 2 years such results were reversed and there was a significantly higher returns for stocks with poor previous performance than stocks with high previous performance.

Dechow et al. (2000) and Cohen et al. (2002) examined the relationship between net cash flows, which is the difference between profitability and investment, and stock returns. The findings of both suggested that positive net cash flows results in a significant high stock returns. In the same way, Welch (2004) attempted to test the profitability effect on US corporations' stock returns and found that profitable firms results in higher returns than unprofitable firms.

Novy-Marx (2013) examined the role of profitability (measured as the ratio of firm's gross profits to its assets) in explaining stock returns. He demonstrated critical evidence that showed a strong relationship between profitability and average returns and adding the profitability factor in predicting stock returns will help in explaining unexplained stock returns and reducing the overall portfolio volatility. That is he found that current profitability is a good predictor of future profitability, and future profitability is a good predictor of higher returns. Such findings disagree with Fama and French (1993) who suggested that low profitability results in higher returns. The findings also contradict Carlson et al. (2004), Zhang (2005) and Novy-Marx _. . 
$(2009,2011)$ who suggested that profitable firms results in lower returns than unprofitable firms.

Based on Novy-Marx (2013) critical findings, Fama and French (2013) presented a four factor model for expecting stock returns. They examined whether we can explain the average return variations that couldn't be explained by three factor model by adding the profitability factor to the model. Even though, the GRS tests reject the model, empirically the results showed that the model could describe average returns well for portfolios sorted on size-B/M, size-OP, and size-B/M-OP. It worth mentioning that the four factors intercepts for size-OP portfolios were all almost close to zero.

\section{Research methodology:}

In this study, proxy specifications of (Fama and French, 2014) four-factor model is estimated in order to produce stylized facts of the Egyptian market:

Rit $(\mathrm{t})=\mathrm{a}+\mathrm{B} 1$ (Beta) $+\mathrm{B} 2$ (size it) $+\mathrm{B} 2$ (value it) $+\mathrm{B} 3$ (earnings it) + eit.Where:(it) is the firm index at time ' $t$ ',

- (Rit) is the simple annual rate of return of firm ' $\mathrm{i}$ ' at time ' $\mathrm{t}$ ' calculated as $\mathrm{P}(\mathrm{t})-\mathrm{P}(\mathrm{t}-1) / \mathrm{P}(\mathrm{t}-1)$,

- (Beta) is a state variable that purports to F\&F market risk premium is measured as $\operatorname{COV}\left(r_{i}, r_{m}\right) / \operatorname{Var} r_{m}$

- (size it) is the size of firm ' $i$ ' at time ' $t$ ' calculated as the natural logarithm of market value of equity (i.e., the share price * the no. shares outstanding), (value it) is the value 
index of firm ' $i$ ' at time ' $t$ ' calculated as book value / size where book

- value is simply total assets - total debt (i.e., total equity on the balance sheet), (earnings it) is accounting earnings (i.e., net income) of firm ' $i$ ' at time ' $t$ ' normalized by book value, (a) is an intercept and (eit) is an error term.

The data set is the panel of all publicly traded firms from 2005 to 2007, excluding [1] financial firms due to their idiosyncratic nature [2] negative book value of equity firms so as to mitigate outliers' effect and produce more robust parameter estimates, and [3] firms with missing financial or market data. The data selection criteria yield 118 firms. The data was collected from the published financial statements obtained from the companies' official websites, the Egyptian stock exchange official website, and Egypt for information dissemination.

\section{Study Results:}

First: BETA

Figure 4-3 The time series for (BETA) BETA

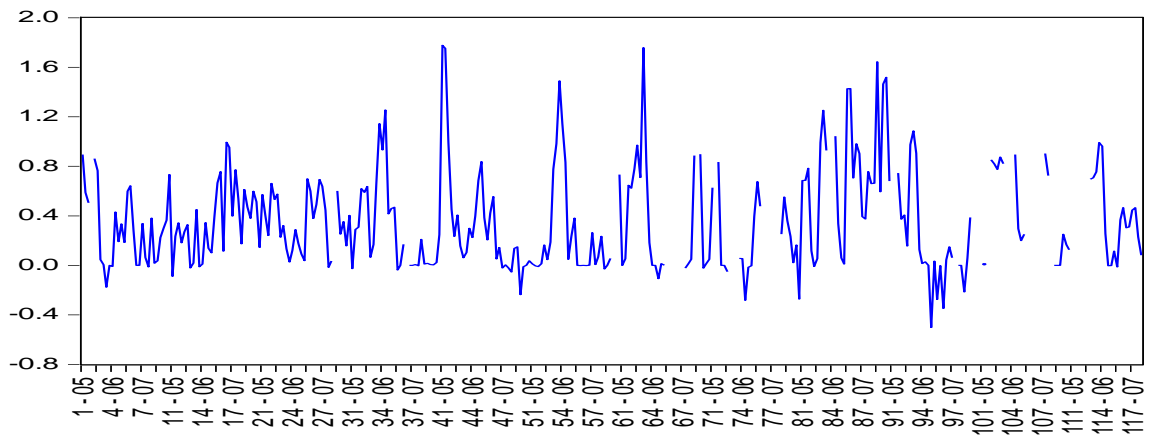

H0:- BETA time series follows normal distribution. 
H1:- BETA time series does not follow normal distribution.

The previous figure shows that the data related to (BETA) variable does not follow a general upward or downward trend which is the data is relatively stable, so the problem of unit root does not exist.

Figure 4-4Descriptive statistics (Beta)

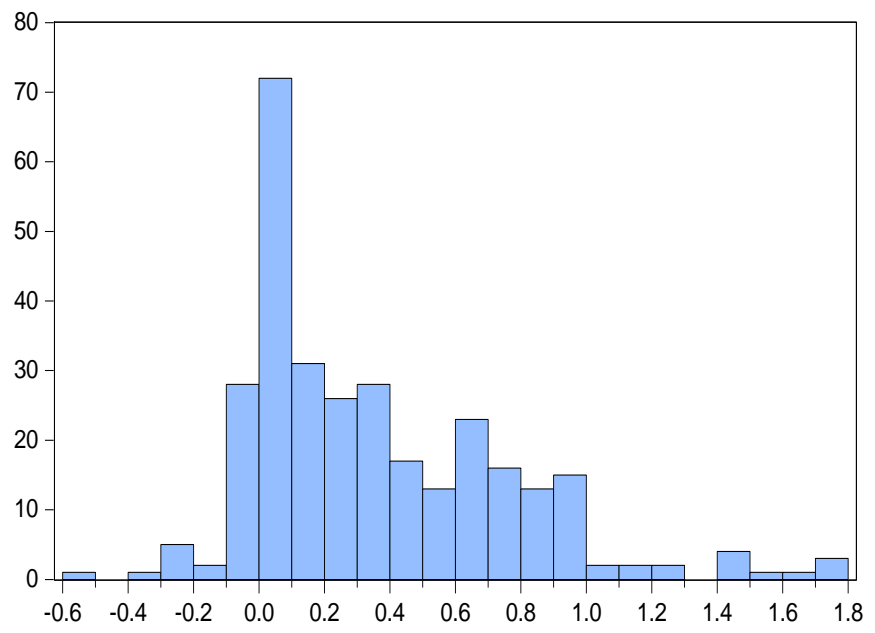

\section{Series: BETA}

Sample 20052007

Observations 306

Mean

Median

Maximum

Minimum

Std. Dev.

Skewness

Kurtosis

Jarque-Bera

Probability
0.355620

0.249667

1.777032

$-0.500802$

0.399866

1.046671

4.029023

69.37239

0.000000

The descriptive measures of (BETA) demonstrate that the value of the mean approaches to be equals to the value of the median which gives initial signal on data normality.

while such results were not found when using (Jarque Bera) test, as the distribution probability was (.000) which is lower than the significance level (.05) which means that the data does not follow normal distribution. 
Egypt's Capital Market Firm-Specific Fundamentals Pre-financial ......

\section{Second: LOSIZE}

Figure 4-5The time series for (LOSIZE)

LOSIZE

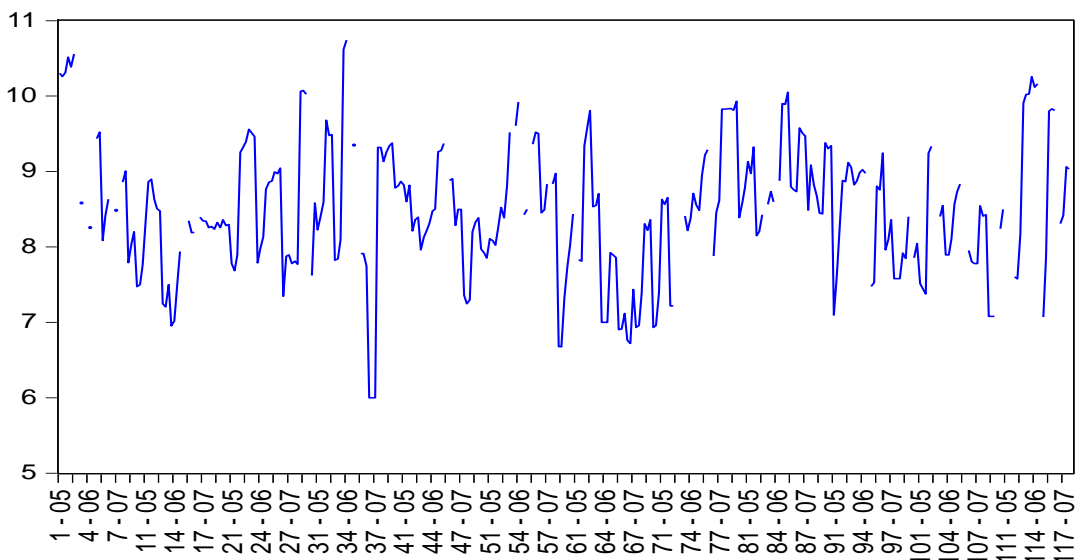

The figure shows that the data is fluctuating and does not follow any general trend that is the series is relatively stable, so the problem of unit root does not exist.

\section{Figure 4-6Descriptive statistics (LOSIZE)}

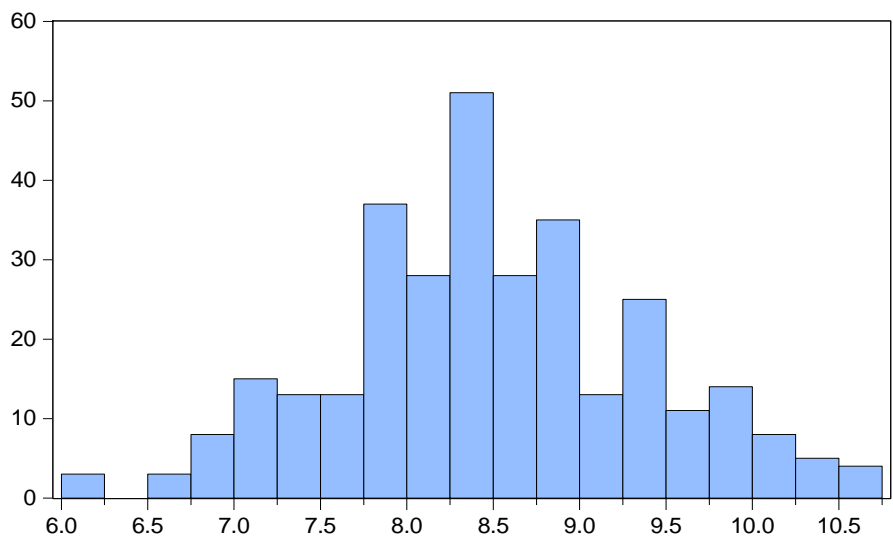

Series: LOSIZE

Sample 20052007

Observations 314

Mean

8.482034

Median 8.437545

Maximum 10.74246

Minimum

6.000000

Std. Dev.

0.881535

Skewness

0.021009

Kurtosis

2.924258

Jarque-Bera

0.098156

Probability 0.952107 
The descriptive measures of (LOSIZE) demonstrates that the data is following normal distribution as the (Jarque - Bera) test demonstrates that the significance level is 0.952 which is higher than the error level which means that we are accepting the null hypothesis (H0) stating that the data is following a normal distribution will be accepted.

\section{Third: LOEARNING}

Figure 4-7The time series for (LOEARNING)

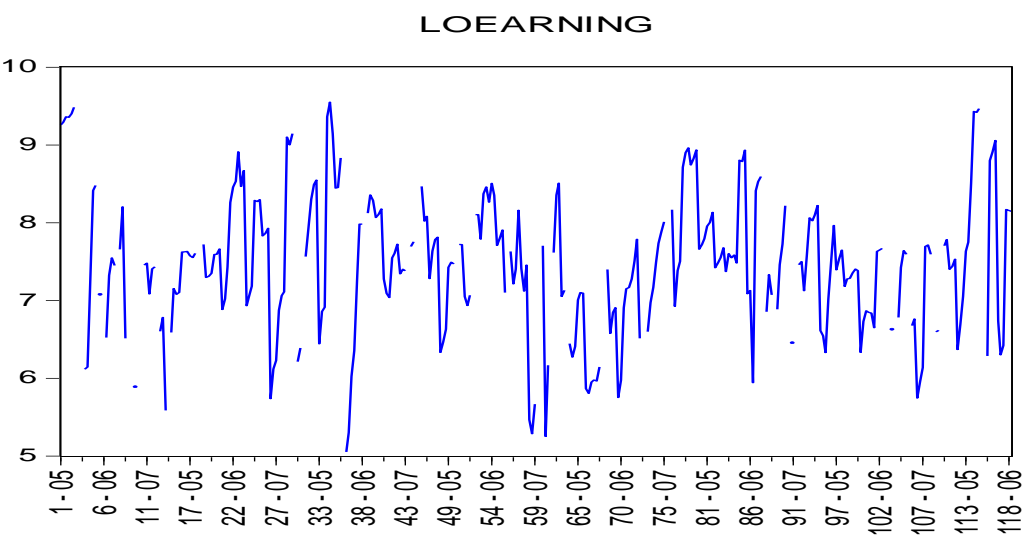

The figure illustrates that the data is stable and does not follow any trend related to time, which is the data are stable, so the problem of unit root does not exist.

In addition, it was found that the series follow a normal distribution as the probability of (Jarque - Bera) test showed that it is equal (.946) which is higher than the error level. So, H0 stating that the series is following normal distribution will be accepted. 
Figure 4-8Descriptive statistics (LOEARNING)

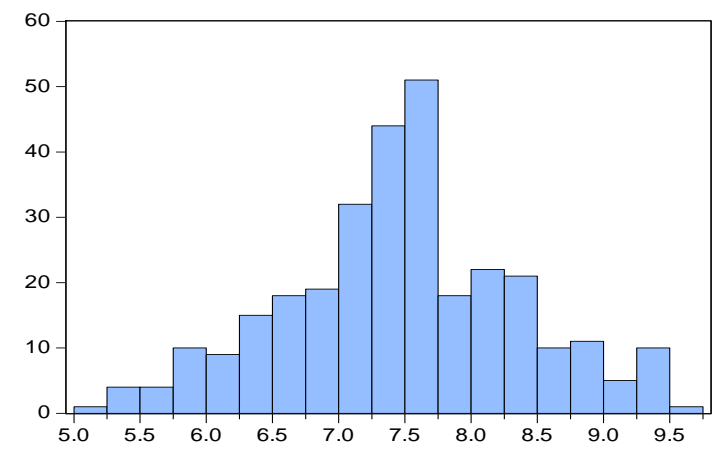

\begin{tabular}{|ll|}
\hline \multicolumn{2}{|l|}{ Series: LOEARNING } \\
Sample 2005 2007 \\
Observations & 305 \\
Mean & 7.470370 \\
Median & 7.482672 \\
Maximum & 9.550227 \\
Minimum & 5.053309 \\
Std. Dev. & 0.888683 \\
Skewness & -0.022852 \\
Kurtosis & 2.918366 \\
& \\
Jarque-Bera & 0.111237 \\
Probability & 0.945900 \\
\hline
\end{tabular}

\section{Forth: LOVALUE}

Figure 4-9The time series for (LOVALUE)

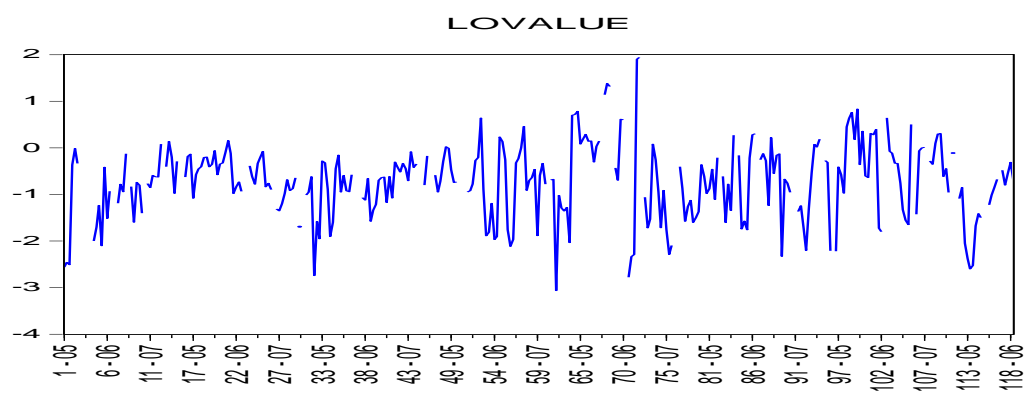

The series does not take a general trend based on time; that is the data is stable, so the problem of unit root does not exist. In addition, the series follow the normal distribution as the probability of (Jarque - Bera) test showed that it equals (.165) which is higher than the error level, so H0 stating that the series follow normal distribution will be accepted. 
Figure 4-10Descriptive statistics (LOVALUE)

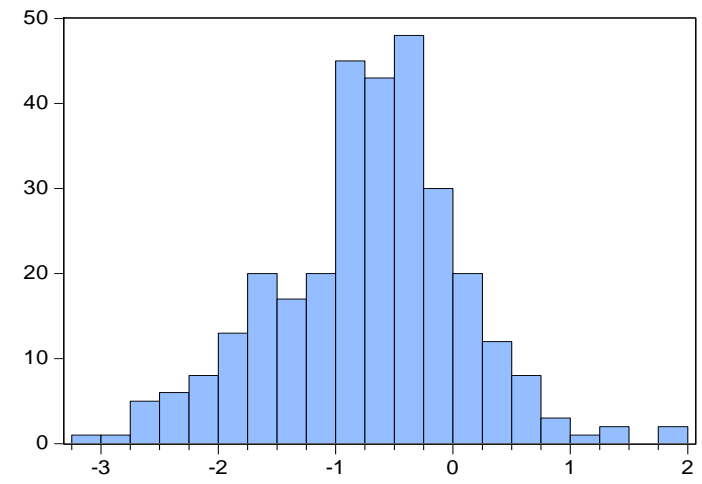

\begin{tabular}{|ll}
\hline \multicolumn{2}{l}{ Series: LOVALUE } \\
Sample 2005 2007 \\
Observations & 305 \\
Mean & -0.718954 \\
Median & -0.645109 \\
Maximum & 1.943274 \\
Minimum & -3.064849 \\
Std. Dev. & 0.806447 \\
Skewness & -0.119933 \\
Kurtosis & 3.475446 \\
& \\
Jarque-Bera & 3.603891 \\
Probability & 0.164978
\end{tabular}

Fifth: RIT

Figure 4-11The time series for (RIT)

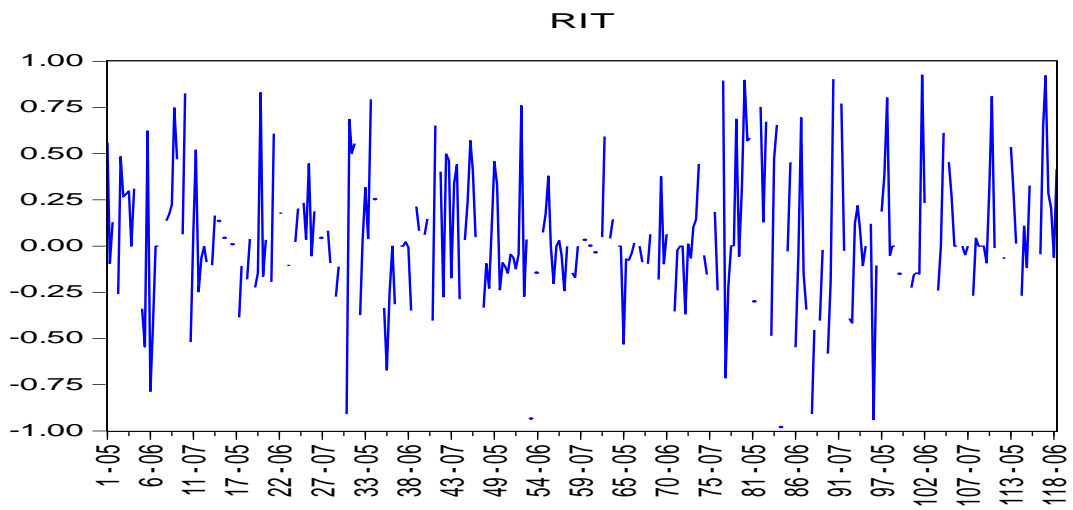

The figure shows that the series does not follow a general trend based on time that is the data is relatively stable, so the problem of unit root does not exist. In addition, the series follows a normal distribution as the probability of (Jarque - Bera) test illustrated that it equals (.115) which is higher than the error level so $\mathrm{HO}$ stating that the series is following normal distribution will be accepted. 
Egypt's Capital Market Firm-Specific Fundamentals Pre-financial ...... Ahmed Mohamed Moataz Abd El Salam

Figure 4-12Descriptive statistics (RIT)

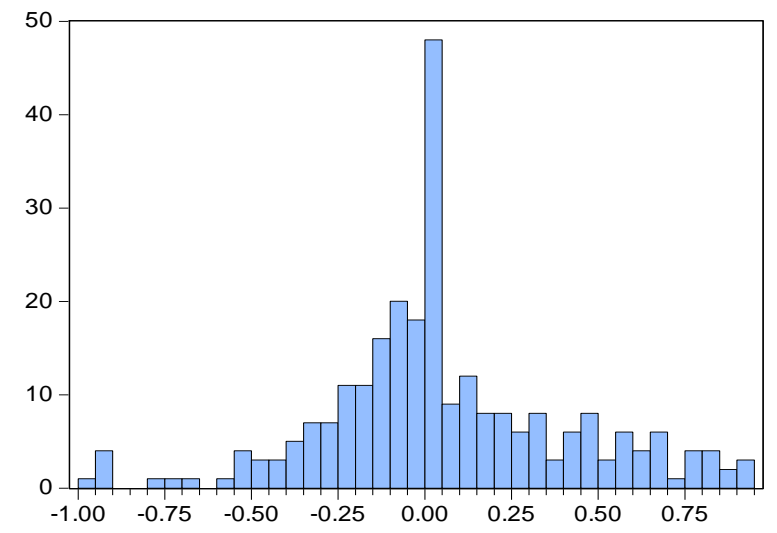

\begin{tabular}{|ll}
\hline \multicolumn{2}{|l|}{ Series: RIT } \\
Sample 2005 2007 \\
Observations 263 \\
Mean & 0.053985 \\
Median & 0.000000 \\
Maximum & 0.925110 \\
Minimum & -0.982155 \\
Std. Dev. & 0.356903 \\
Skewness & 0.137674 \\
Kurtosis & 3.565103 \\
& \\
Jarque-Bera & 4.330270 \\
Probability & 0.114734
\end{tabular}

Sixth: The regression model

The model depends on annual data during the period from 2005 to 2007. The independent variables and the dependent variable for the time series were entered as following:

- The dependent variable: RIT

- The independent variables: BETA, LOEARNING, LOSIZE and LOVALUE

Table 4-3 The Regression model's coefficients

\begin{tabular}{|c|c|c|c|c|}
\hline Variables & Coefficients & $\begin{array}{c}\text { Standard } \\
\text { error }\end{array}$ & T test & Significance \\
\hline D(LOEARNING) & $\mathbf{- 0 . 2 5 0 4 9}$ & $\mathbf{0 . 1 2 3 5 3 5}$ & $\mathbf{- 2 . 0 2 7 6 8 4}$ & $\mathbf{0 . 0 4 9 6}$ \\
\hline D(LOSIZE) & $\mathbf{1 . 9 0 5 1 8 1}$ & $\mathbf{0 . 2 7 6 9 3 2}$ & $\mathbf{6 . 8 7 9 5 9 9}$ & $\mathbf{0 . 0 0 0 0}$ \\
\hline D(LOVALUE) & $-\mathbf{0 . 1 6 7 7 9 5}$ & $\mathbf{0 . 0 7 2 6 7}$ & $-\mathbf{- 2 . 3 0 8 9 9 2}$ & $\mathbf{0 . 0 2 6 5}$ \\
\hline C & $\mathbf{0 . 0 0 4 6 7 1}$ & $\mathbf{0 . 0 2 0 5 3 2}$ & $\mathbf{0 . 2 2 7 4 9 5}$ & $\mathbf{0 . 8 2 1 3}$ \\
\hline
\end{tabular}

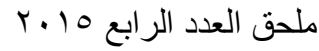


Egypt's Capital Market Firm-Specific Fundamentals Pre-financial ...... Ahmed Mohamed Moataz Abd El Salam

Although the strong explanatory power of such model that reached $(91.6 \%)$, the standardized residual of the model does not follow normal distribution. which is an essential requirement and is considered an important indicator on the quality of the model.

Figure 4-13 Descriptive statistics (residuals)
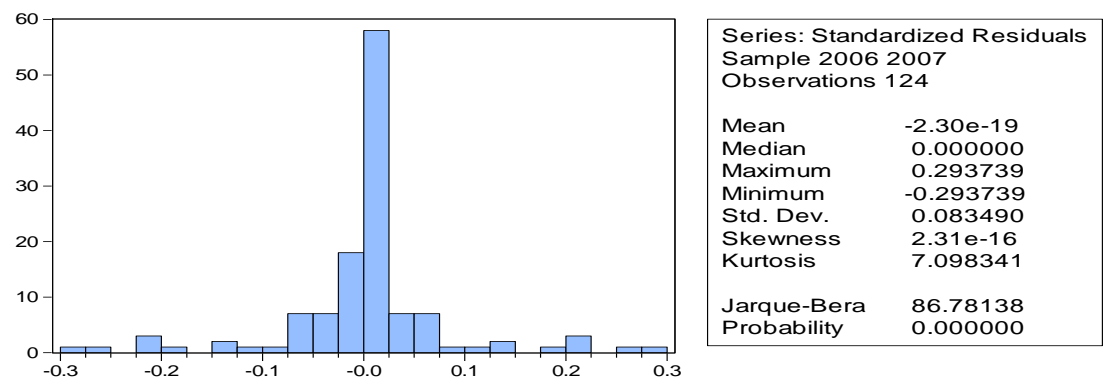

So, it is not considered the best model, as a result some variables were excluded as they cause some problems and limitations such as the problem of multi-co-linearity.As there is a strong correlation between (size) and both (earning, value).

\begin{tabular}{|c|c|c|c|c|c|}
\hline \multicolumn{5}{|c|}{ Table 4-4 Correlation analysis between the explanatory variables (matrix) - } \\
period (1) \\
\cline { 1 - 1 } LOVALUE & LOSIZE & LOEARNING & BETA & RIT & Probability \\
\hline & & & 1 & $-\mathbf{0 . 1 1 4}$ & \multirow{2}{*}{ BETA } \\
\hline & & & ---- & 0.137 & \\
\hline & & 1 & 0.236 & 0.074 & \multirow{2}{*}{ LOEARNING } \\
\hline & & ---- & 0.0018 & 0.338 & \\
\hline & 1 & 0.837 & 0.438 & 0.015 & \multirow{2}{*}{ LOSIZE } \\
\hline & ---- & 0.000 & 0.000 & 0.848 & \\
\hline---- & -0.637 & -0.346 & -0.320 & -0.108 & \multirow{2}{*}{ LOVALUE } \\
\hline & 0.000 & 0.000 & 0.000 & 0.1572 & \\
\hline
\end{tabular}


Egypt's Capital Market Firm-Specific Fundamentals Pre-financial ...... Ahmed Mohamed Moataz Abd El Salam

From the previous table, there are a high correlation between LOSIZE and LOEARNING and also there are a high correlation between LOVALUE and LOVALUE. The researcher exclude both LOSIZE and LOEARNING and regress only LOVALUE as it's the only variable that have a high significant correlation with return as showed in the appendix.

Table 4-5 The new model Coefficients

\begin{tabular}{|c|c|c|c|c|}
\hline Variables & Coefficients & $\begin{array}{c}\text { Standard } \\
\text { error }\end{array}$ & T test & Significance \\
\hline D(LOVALUE) & $\mathbf{- 0 . 2 3 9 9 2 9}$ & $\mathbf{0 . 0 6 4 5 9 6}$ & $\begin{array}{c}- \\
\mathbf{3 . 7 1 4 2 7 3}\end{array}$ & $\mathbf{0 . 0 0 0 4}$ \\
\hline C & $\mathbf{0 . 0 2 6 0 4 1}$ & $\mathbf{0 . 0 2 0 6 7 9}$ & $\mathbf{1 . 2 5 9 2 9 2}$ & $\mathbf{0 . 2 1 2 6}$ \\
\hline
\end{tabular}

The previous table shows that (LOVALUE) affects (RIT), as the variable significance reached (0.000) which is a significant at a confidence level $99 \%$. The explanatory power of such variable in explaining and interpreting the changes that may occur to the dependent variable (RIT) was (0.75) which is a good explanatory power.

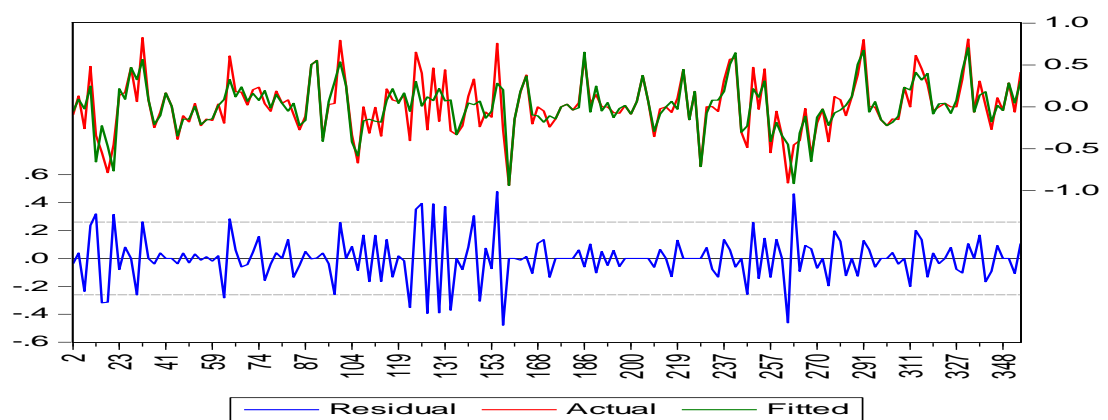

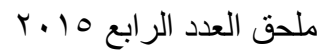


Egypt's Capital Market Firm-Specific Fundamentals Pre-financial ...... Ahmed Mohamed Moataz Abd El Salam

Also the residuals for this model are not following the normal distribution.

Figure 4-14Descriptive statistics (new residuals)

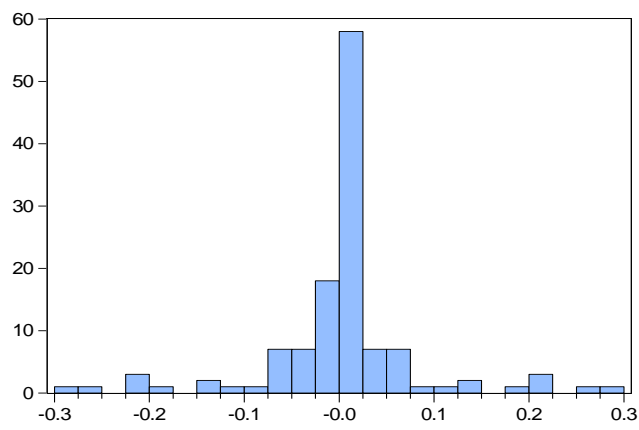

\begin{tabular}{|lc|}
\hline \multicolumn{2}{|l|}{ Series: Standardized Residuals } \\
Sample 2006 2007 \\
Observations 124 \\
Mean & $-2.30 \mathrm{e}-19$ \\
Median & 0.000000 \\
Maximum & 0.293739 \\
Minimum & -0.293739 \\
Std. Dev. & 0.083490 \\
Skewness & $2.31 \mathrm{e}-16$ \\
Kurtosis & 7.098341 \\
& \\
Jarque-Bera & 86.78138 \\
Probability & 0.000000 \\
\hline
\end{tabular}

Effects test (Cross-section and Period)

Table 4-6 Effects test

\begin{tabular}{|c|c|c|c|}
\hline Effects Test & Statistic & d.f. & Prob. \\
\hline Cross-section F & $\mathbf{1 . 6 4 4 9 6 8}$ & $(\mathbf{9 8 , 6 3 )}$ & $\mathbf{0 . 0 1 7 5}$ \\
\hline $\begin{array}{c}\text { Cross-section } \\
\text { Chi-square }\end{array}$ & $\mathbf{2 0 8 . 1 8 7 2 2 2}$ & $\mathbf{9 8}$ & $\mathbf{0 . 0 0 0 0}$ \\
\hline Period F & $\mathbf{5 . 6 7 4 9 5 9}$ & $(\mathbf{1 , 6 3 )}$ & $\mathbf{0 . 0 2 0 2}$ \\
\hline $\begin{array}{c}\text { Period Chi- } \\
\text { square }\end{array}$ & 14.144986 & 1 & $\mathbf{0 . 0 0 0 2}$ \\
\hline $\begin{array}{c}\text { Cross- } \\
\text { Section/Period F }\end{array}$ & 1.645589 & $(99,63)$ & 0.0173 \\
\hline $\begin{array}{c}\text { Cross- } \\
\text { Section/Period } \\
\text { Chi-square }\end{array}$ & $\mathbf{2 0 9 . 4 3 0 6 9 1}$ & 99 & 0.0000 \\
\hline
\end{tabular}


Egypt's Capital Market Firm-Specific Fundamentals Pre-financial ...... Ahmed Mohamed Moataz Abd El Salam

The previous table shows that both sectors and time have significant effect on regression model equation, and that is what was taken into consideration in the final model equation. Therefore, the final estimation equation for period one is:

$\mathrm{RIT}=\mathrm{C}(1) * \mathrm{D}($ LOVALUE $)+\mathrm{C}(2)+[\mathrm{CX}=\mathrm{F}, \mathrm{PER}=\mathrm{F}]$

Where:-

- $\mathrm{C}(1)$ refers to coefficient of $\mathrm{D}($ LOVALUE) factor

- $\mathrm{C}(2)$ refers to a constant

$\mathrm{RIT}=-0.239928719122 * \mathrm{D}($ LOVALUE $)+0.0260408822124+$ $[\mathrm{CX}=\mathrm{F}, \mathrm{PER}=\mathrm{F}]$ 


\section{Conclusion:}

The qualitative study, that evaluates the extent to which idiosyncratic risk factors organize market facts during 2005-2007 signifying the economic environment pre-financial crisis based on beta and firm-specific fundamentals, namely, size, value, and accounting earnings, demonstrates that: the data related to all variables does not follow a general upward or downward trend (i.e. the data is relatively stable) and all variables are following a normal distribution except for beta. The period data face the problem of multi-co-linearity between (size) and both (earning, value). However, the results showed that the value is the most important variable in explaining RIT in period one as the explanatory power reaches $0.75 \%$ of return and it was negatively correlated with return with sensitivity equal -0.239929 . Also, the results showed that the residuals of the regression model doesn't follow normal distribution even after solving the problem of multi-co-linearity between (size) and both (earning, value) which put doubts on the model ability to significantly explain contemporaneous variation in excess returns during period one .The effect test also shows that both sectors and time have significant effects on regression model equation. 


\section{Egypt's Capital Market Firm-Specific Fundamentals Pre-financial Ahmed Mohamed Moataz Abd EI Salam}

\section{References:}

Fama, E.F. \& French, K.R., 2013.A Four-Factor Model for the Size, Value, and Profitability Patterns in Stock Returns. Fama-Miller working Paper.

Ross, S.A., 1976. The Arbitrage Theory of Capital Asset Pricing. Journal of economic theory, Vol.13, pp.341-360.

Hamao, Y., 1988, an empirical examination of the arbitrage pricing theory. Japan and the world economy, Vol.1, PP. 45-61.

Chen, S.-N., 1986.An intertemporal capital asset pricing model under heterogeneous beliefs.Journal of Economics and Business, 38(4), pp.317330.

Antoniou, A., Garrett, I. \& Priestley, R., 1998.Macroeconomic variables as common pervasive risk factors and the empirical content of the arbitrage pricing theory. Journal of empirical finance, pp.221-240.

Copeland,TE, Weston,JF and Shastri, KS, 2005, Financial Theory and Corporate Policy, Fourth Edition, Person Addison Wesley.

Ball, R., 1978. Anomalies in relationships between securities' yields and yield-surrogates.Journal of Financial Economics, 6(2-3), pp.103-126.

litzenberger, R. H., \&Ramaswamy, K., 1979. The effect of personal taxes and dividends on capital asset prices.Journal of financial economics, Vol. 7, pp. 163-195.

Daniel, K.\& Titman, S., 1997. Evidence on the Characteristics of Cross Sectional Variation in Stock Returns.The Journal of Finance, Volume LII No1, pp.1-33.

Banz, R.W., 1981. The relationship between return and market value of common stocks.Journal of Financial Economics.Vol.9, pp.3 -18.

Basu, S., 1983.The relationship between earnings' yield, market value and return for NYSE common stocks, Journal of Financial Economics.Vol. 12, pp.129-156.

Chan, L.K.C., Hamao, Y. \&Lakonishok, J., 1991. Fundamentals and Stock Returns in Japan ,The Journal Of Finance 46(5), pp.1739-1764.

Hawawini, G. \&Keim, D.B., 2000. The cross section of common stock returns : a review of the evidence and some new findings. Security market 
imperfections in worldwide equity markets.-Cambridge [u.a.] : Cambridge Univ. Press, ISBN 0521571383. p. 3-43

Fama, E.F. \& French, K.R., 1992.The Cross-Section of Expected Stock Returns., The journal of financeXLVII(2), pp. 427- 465.

Fama, E.F. \& French, K.R., 1993.Common risk factors in the returns on stocks and bonds.Journal of Financial Economics, 33(1), pp.3-56.

Fama, E.F. \& French, K.R., 1995.Size and Book-to-Market Factors in Earnings and Returns., The journal of finance, Vol. 50(1), pp.131-155.

Penman, S. H.,1991. An Evaluation of Accounting rate of return.Journal of accounting, auditing, and finance. Vol.6, pp.233-255.

Nguyen, A., Faff, R., \&Gharghori, P., 2009. Are the Fama-French factors proxying news related to GDP growth? The Australian evidence.Review of Quantitative Finance and Accounting, Vol. 33(2), pp.141-158.

Dechow, P.M., Hutton, A.P. \& Sloan, R.G., 2000. An empirical assessment of the residual income valuation model.Journal of accounting and economics, Vol. 26, PP. 1-43.

Cohen, R.B., Gompers, P.A., Voulteenaho, T., 2002. Who underreacts to cash-flow news? evidence from trading between individuals and institutions. Journal of financial economics, Vol. 66, pp.409-462.

Novy-marx, R., 2013. The other side of value: The gross profitability premium. Journal of Financial Economics, Vol.108(1), pp.1-28. 